\title{
THE PRACTICAL APPLICATION OF THE RHESUS BLOOD FACTOR TO THE ART AND PRACTICE OF OBSTETRICS
}

\author{
By D. R. L. Stevenson, M.B., Ch.B., F.R.C.S., M.R.C.O.G.
}

\section{Introduction}

The subject has been chosen for three reasons. First, because in the space of just a few years the rhesus blood factor has assumed world-wide interest and import, and has already come to merit a most important place in the realm of obstetrics. Secondly, its practical significance does not yet seem to be fully appreciated or realized, and thirdly, study has proved this subject to be much more complicated than was at first thought.

A considerable amount of knowledge has been accumulated in these last few years, but there is still much more to be found out, both practically, and on the research side as well. The picture is incomplete and its completion depends on the close interdigitation of the practical with the research side, and the seeing that no available material is missed.

The purpose of this article is not to diverge into research problems or those relating to blood transfusion, but to indicate the particular influence that this recent research has on practical obstetrics. It is essential, however, to include brief references to the research that has made this practical application of it not only possible, but necessary.

\section{The Rhesus Blood Factor}

The rhesus, or Rh factor, is a new blood agglutinogen. In - 1940, Landsteiner and Weiner injected red cells of the Rhesus monkey into rabbits and guinea pigs. This produced an immune serum, which agglutinated the red cells of 85 per cent. of American Whites, and failed to react with the other 15 per cent. Human bloods agglutinated by this serum were called $\mathrm{Rh}$ positive (denoted $\mathrm{Rh}$ or $\mathrm{R}$ ), and those which did not, $\mathrm{Rh}$ negative (denoted rh or $\mathbf{r}$ ).

Arising from the investigation of certain haemolytic transfusion reactions, which showed them due to $R h$ positive blood being given to $R h$ negative subjects, or vice versa, it was noted that where such reactions occurred after transfusions in the puerperium, there was often an associated foetal abnormaltiy.

\section{The Genotypes of the Rh Factor}

It is advisable, before discussing this associated foetal abnormality, to set out clearly what is meant by the genotypes of the $\mathrm{Rh}$ factor. In 80 per cent. of cases the $R h$ genotypes can be accurately recognized serologically: They represent the fundamental constitution of given individuals. The human cell possesses 24 pairs of chromosomes. At fertilization, with the union of the sperm and ovum, one chromosome of each new pair formed comes from the male side, and the other from the female side. Thus, as far as the $\mathrm{Rh}$ factor is concerned, the foetus derives 50 per cent. of its genotype from the father, and 50 per cent. from the mother.

Much, then, depends on whether the parents are homozygous, that is, their pairs of chromosomes are identical as regards $\mathrm{Rh}$ factor, or whether they are heterozygous, where the pairs of chromosomes are not identical as regards Rh.

A homozygous person is denoted $\mathrm{Rh} R \mathrm{Rh}$ (R.R.) on the positive side, and rh th (r.r.) on the negative. A heterozygous person is denoted Rh rh (R.r.), that is, a combination of positive and negative. The $\mathrm{Rh}$ negative gene (rh) is recessive, so that a heterozygous person is always $R h$ positive. 
It can be seen, therefore, that a homozygous $\mathrm{Rh}$ positive ( $\mathrm{Rh} R \mathrm{R}$ ) father when mated to an $\mathrm{Rh}$ negative ( $\mathrm{rh} \mathrm{rh}$ ) wife, can only produce a heterozygous but yet $\mathrm{Rh}$ positive child. Once his wife has become sensitized to his $R h$ positive, his chance of producing an unaffected child is almost nil. On the other hand, a heterozygous father ( $\mathrm{Rh} \mathrm{rh}$ ) mated to an $\mathrm{Rh}$ negative (rh rh) wife, has a 50 per cent. chance of producing an $\mathrm{Rh}$ negative and so unaffected child.

It is, however, not quite such plain sailing as this, because the various allelomorphs of the $\mathrm{Rh}$ gene have to be taken into account, as each may produce a different agglutinogen. Also, what can be termed reverse $\mathrm{Rh}$ reaction can occur, that is, a homozygous $\mathrm{Rh}$ positive ( $R h$ Rh) wife may be sensitized to her husband's $\mathrm{Rh}$ negative gene (rh $\mathrm{rh}$, or $\mathrm{Rh} \mathrm{rh}$ ).

The writer's opinion is that the genotype is all important as regards the prognosis and treatment in cases where the $\mathrm{Rh}$ factor is involved, and that such cases can neither be intelligently nor scientifically handled, unless the genotypes of both parents and the child are known.

Examples will be given later of how it is possible to presume, in the absence of genotypes, that a new-born baby is suffering or will suffer from 'haemolytic disease of the new born,' and that its life has been saved by immediate transfusion. The genotypes in such cases will often prove that the occurrence of haemolytic disease of the new born was an impossibility, that the transfusion was quite unnecessary, and the claim to success entirely erroneous.

\section{Relationship of the Rh Factor to Obstetrics Generally}

In r941, Levine, Burnham, Englewood, Katzin and Vogel demonstrated that many transfusion reactions in the puerperium were definitely associated with what Parsons has since termed haemolytic disease of the new born, comprised of hydrops foetalis, erythroblastosis neonatorum, icterus gravis neonatorum and haemolytic anaemia.

This work has been amply confirmed by Boorman, Dodd and Mollison, and by Taylor, Race and others, and can now be regarded as proved fact.
The condition is due to isoimmunization of the mother to an antigen present in the foetal erythroblasts, because of the fact that an $\mathrm{Rh}$ negative mother is carrying an $\mathrm{Rh}$ positive foetus. An antibody is thus formed in the mother's blood, and it crosses the placental membrane to the foetal circulation, and there destroys foetal red cells, producing the condition of intravascular haemolysis.

Javert (1937) estimated the occurrence of haemolytic disease of the new born as I : 400 births. Taylor (1944) estimated it at I : 200 births.

Obviously, therefore, haemolytic disease of the new born is a definite cause of infant mortality. It is also known that survival from it in the past, especially after the onset of kernicterus, is associated with mental deficiency.

\section{The Rh Factor and Antenatal Care}

The ideal is obviously the routine determination of the genotype of husband and wife in all cases of pregnancy. The future may bring this, but at present the laboratories of the country have neither the staff nor the materials to do it.

In the writer's own area, at all antenatal clinics, the mother's blood is tested as to whether it is $\mathrm{Rh}$ positive or negative. Given a negative result, the family genotypes are investigated. This is also done even if the mother is $\mathrm{Rh}$ positive, in any case where the previous history suggests $R h$ factor involvement. This is not perfect, but is a step in the right direction.

It is apparent that the previous history should be taken with even more detailed care and thought than ever. In every case of abortion for no apparent reason, stillbirth, intrauterine death of the foetus, maceration, death soon after birth, especially if associated with hydrops or icterus, premature labour, abnormality of the foetus, and mental deficiency, the family genotypes, including the affected foetus, and any living children, should be investigated.

In cases where the family genotypes indicate the possibility of $\mathrm{Rh}$ factor involvement, the mother's blood should be routinely examined, throughout the pregnancy, for antibody. It must be borne in mind, however, that antibody 
is rarely demonstrable before the 32 nd week of pregnancy. In some cases, the mother may show a certain degree of icterus near full term or in the early puerperium.

\section{The Rh Factor and the Confinement}

This must be considered under two separate headings.

(a) Cases where the $\mathrm{Rh}$ factor involvement can be anticipated.

(b) Cases where the Rh factor involvement has not been anticipated.

\section{(a) The anticipated case}

Either the previous history or the finding by routine examination of an $\mathrm{Rh}$ negative mother, have led to investigation of the family genotypes. If the investigation has been a routine one, the case should be kept under strict supervision and all preparations made to cope with trouble should it arise. For reasons not as yet known, isoimmunization of the mother does not occur in every case where the combination of genotypes renders it possible.

Where the previous history shows that haemolytic disease of the new born has already occurred in the family, the outcome of the case depends on the actual combination of family genotypes.

If it is a homozygous $R h$ positive father $\left(R h_{1} R h_{1}\right)$ and an $R h$ negative mother ( $\left.\mathrm{hh} \mathrm{rh}\right)$ or vice versa, and she has already been sensitized to her husband's Rh gene, then haemolytic disease of the new born can be definitely predicted, whether or not antibody is ever demonstrated in the mother's blood.

The different allelomorphs of the $\mathrm{Rh}$ gene seem definitely to have a bearing on the outlook. Where, for instance, a father $\left(R h_{1} R h_{2}\right)$ is mated to a negative mother ( $\mathrm{rh} \mathrm{rh}$ ) it seems possible for her to be sensitized to his $R h_{1}$ and produce babies suffering from haemolytic disease of the new born, and yet in a subsequent pregnancy produce a child of genotype $R h_{2} r h$, which is unaffected.

The appearance of $\mathrm{Rh}$ antibody in the mother's serum, is proof positive of $\mathrm{Rh}$ factor involvement. The non-detection of antibody, however, by no means excludes the possibility of haemolytic disease of the new born. This means that there may be antibodies as yet unidentified, or that present techniques are inadequate.
A significant increase in the cases of demonstrable antibody can be shown by the special techniques such as those of Weiner, Race, etc., for eliciting ' incomplete antibody.'

Sometimes antibody can be detected in the mother's serum 7-10 days after the confinement, where previously all findings were negative. At other times, a child is born which rapidly dies due to kernicterus, and at no time during the pregnancy or the puerperium has it been possible to demonstrate antibody.

It has been recommended that where haemolytic disease of the new born can be predicted, that Caesar ean section be performed at approximately the 38 th week, followed by immediate transfusion of the child. The reason given is that kernicterus probably starts to develop some two weeks prior to full term. It is also claimed that affected babies are prone to asphyxia during their passage through the birth canal.

That kernicterus does commence to develop at, or soon after, birth, and that it progresses rapidly, is not disputed. The writer, however, cannot subscribe to an affected foetus being more prone than any other to asphyxia during birth.

It would seem, that for the present state of knowledge, the pendulum has swung too far. Before such a radical line of treatment could recommend itself to those who practise obstetrics, fuller proof will have to be given (a) that kernicterus does develop before full term, (b) that normal labour in a multipara prejudices the child's chance of survivalbecause labour can always be induced at the 38th week or earlier, (c) that the results obtained by Caesarean section eclipse those by induction.

The writer's experience in predictable cases is that the immediate and distant grave prognosis for the child constitute a very definite contraindication to radical methods, and that conservative lines of treatment can achieve equivalent results. If the titre of a demonstrable antibody rises towards full term, as it sometimes does, immediate induction of labour is indicated.

When, however, by whatever means the child is delivered, the following procedure should at once be carried out. 
(a) Taking care not to foul with Wharton's jelly, which inhibits agglutination, two specimens of cord blood are taken, one with heparin, the other without.

(b) Specimen of mother's blood from a vein, if one has not very recently been taken.

(c) Blood films from the child.

The child's blood is examined for icterus and its genotype determined. The stained films are examined for signs of erythroblastosis. A predominance of early primary erythroblasts over normoblasts is pathognomic of haemolytic disease of the new born.

\section{(b) The non-anticipated case}

No investigation has been done because no suspicions had been aroused.

It is usually a second baby, the first having been quite normal except, of course, that the mother's blood had been sensitized thereby. Sometimes it is a first pregnancy, at other times two, three, or more normal babies have been born before sensitization of the mother has occurred.

The baby may die in utero and become macerated. It may show hydrops foetalis, where birth is usually premature at the 32 nd to $34^{\text {th }}$ week. The degree of hydrops is variable. Ascites may obstruct labour. The placenta is large, anaemic and friable. The child does not survive. $\mathrm{Rh}$ factor investigation should always be done, should the mother of a macerated foetus or of a hydrops foetalis, require transfusion. Fatalities have occurred for want of this. An Rh negative woman, during the child bearing age, should always receive $R h$ negative blood. Diamond has shown a higher incidence of haemolytic disease of the new born in $\mathrm{Rh}$ negative mothers who have previously been transfused with $R h$ positive blood.

The baby may look perfectly normal at birth, at full term. Jaundice, however, may appear a few hours after birth and increase very rapidly. This is icterus gravis neonatorum, as opposed to physiological jaundice, which rarely appears earlier than 48 hours after delivery. These babies may also show haemorrhages into mucous membranes under the skin, or from the umbilicus.

Very soon as the jaundice deepens the baby may develop twitçings, irritability of the cerebral type, followed by deep drowsiness, nystagmus rigidity, local or generalized, or even convulsions. Its general condition deteriorates rapidly, and anaemia becomes obvious, despite the jaundice. This signifies kernicterus, which is characterized pathologically by a bright yellow pigmentation of the nuclear structures of the brain. Death usually occurs on the second, third, or fourth day after birth.

In congenital anaemia, the child may appear normal at birth, or look pale and anaemic. Inside two or three days, however, marked pallor and anaemia can be observed, the skin assuming an almost transparent appearance. At birth the liquor amnii and vernix caseosa often have a yellow or orange colour.

As before, the mother's blood, foetal blood and films are sent for examination as soon as the diagnosis is suspected.

Treatment of the Child Affected with Haemolytic Disease of the New Born

As soon as possible after delivery, and this the writer believes to be most important as regards success, the child is transfused with specially selected blood. This blood is the same $\mathrm{Rh}$ group as the mother (usually $\mathbf{R h}$ negative) and has been matched against her serum. The mother's blood must never be given. The blood must be given intravenously and, if ready and waiting, can be given via the umbilical cord. The malleolar veins, or veins in the arm, however, are more suitable, as the giving of an adequate amount of blood takes considerable time. The amount of blood given is regulated by the size of the child, 200$25^{\circ}$ ccs. being the amount aimed at for a 7 to a $7 \frac{1}{2} \mathrm{lb}$. baby.

The idea behind the transfusion is to "damp down ' the activity of the child's bone-marrow, and so curtail its production of red blood corpuscles as they are sensitive to, and destroyed by, the antibody present in the circulation. The cells of the transfused blood are not sensitized to the antibody, are destroyed more slowly, and so prevent the child dying from anaemia, and avert the onset of kernicterus, both of which may otherwise occur from intravascular haemolysis. Thus, until the antibody has, so to speak, worked itself out, the child is kept alive by the transfusion, or repeated transfusions if necessary. The degree 
of anaemia which shows the rate of intravascular haemolysis, is the guide as to when and how often to transfuse. Frequent haemoglobin estimations are, therefore, necessary, and the more rapidly the percentage falls, the more frequently will transfusion be required.

Once kernicterus has developed, there is no evidence that transfusion plays any helpful part. Those children who survive kernicterus show mental backwardness or deficiency, or imbecility often associated with spasticity and frequently athetoid or choreiform movements.

At present, breast feeding is considered inadvisable even though the milk is found free from antibody. On present knowledge that is no guarantee that it might not contain some, as yet unidentified, antibody.

\section{Prognosis-Immediate and Remote}

\section{A. Immediate}

Gimson (I943) transfused I8 cases with Rh negative blood, and reported 14 'perfect' recoveries and four satisfactory.

Cappell (1944) transfused 17 cases of which I 6 recovered and one, with proved kernicterus, died.

In neither of these reported series were the genotypes of the babies ascertained. Therefore, it is felt that they cannot be taken as giving any true picture of the real prognosis. It is possible, in the absence of the babies' genotypes, that transfusions were given to infants not suffering from haemolytic disease of the new korn.

To obtain a comprehensive picture of the prognosis it is wise to consider the problem as follows :-

(a) A homozygous $\mathrm{Rh}$ positive father mated to an $\mathrm{Rh}$ negative wife or vice versa, where haemolytic disease of the new born has already occurred in some form in the family.

Haemolytic disease can be here predicted. It may manifest itself in several ways for example abortion, death in utero, stillbirth, maceration, foetal abnormality, premature labour with or without hydrops foetalis. If the child is born alive, apparently normal, there is no guarantee that one or repeated transfusions will save its life or prevent the onset of kernicterus. Recovery from kernicterus is almost synonymous with mental deficiency. Once kernicterus has appeared in a family, subsequent children are more liable to develop it.

(b) A heterozygous father mated to an $\mathrm{Rh}$ negative wife.

Here, even though haemolytic disease has already occurred in the family, there is a chance of the baby attaining the same genotype as its mother, and so be unaffected.

Where antibody has been detected during the pregnancy, however, the outlook can be the same as for $(a)$, and can be, even though no antibody has been demonstrable. The only way to find out whether the child has escaped affection, is to ascertain its genotype.

(c) A non-anticipated case of haemolytic disease whatever may be the combination of family genotypes.

Often kernicterus develops, so to speak, with the diagnosis of $\mathrm{Rh}$ factor involvement, and the child may die before blood investigation can be completed or treatment given. Of necessity, there is a definite delay between the onset of the disease and transfusion of the child, and so treatment may fail to save the child or prevent kernicterus. Repeated transfusions are often necessary. The outlook for such children is not good, although some survive.

$(d)$ The anticipated case with genotype combinations as for $(a)$ and $(b)$, and where the child is born alive, at or near full term, and either apparently normal or showing some icterus or anaemia. If kernicterus does not develop, and if the haemoglobin percentage has been stabilized, even though much below normal, by one or more transfusions, the immediate prognosis is reasonably good. Anahaemin injections, $\frac{1}{2}$ cc. daily, and ferri et ammon. cit. by mouth are of considerable benefit, cause a rise of haemoglobin percentage, and may save repetition of transfusion.

The child must be kept under strict supervision and its blood picture checked at intervals. There is no doubt that between the third and sixth month of infant life, some babies tend to relapse again to a condition of severe anaemia, which may prove fatal. The strictest supervision must not be relaxed until the child has been proved to maintain a normal blood picture.

(e) Cases where the family genotypes show that $\mathrm{Rh}$ factor involvement is theoretically possible, but where haemolytic disease of the 
new born has not as yet occurred in the family, and where antibody has not been detected.

First babies are usually, but not always, unaffected. Second babies are often affected, especially with a homozygous combination of genotypes. However, for reasons as yet unexplained, haemolytic disease of the new born does not by any means occur in all cases where it could be expected to do so. Why some women become sensitized and others do not has still to be determined.

\section{B. Remote prognosis}

This is a matter that only time will solve. All immediately successful cases must be followed up as regards their adolescent and adult mental calibre in order to prove that what has been done has been worth while.

\section{Heredity and the Rh Factor}

The $R h$ positive gene is inherited as a mandelian dominant, the $\mathrm{Rh}$ negative gene being recessive. It is inherited quite independently from the A.B.O. groups, and there is no sex linkage.

Race and others (1944), and Levine and Weiner have shown that there are at least seven allelomorphs of the $R h$ gene:- $R h_{1}$, $R h_{2}, R h_{0}, R h^{1}, R h^{11}$, rh and Rhy. These account for 28 clearly defined genotypes. 93 per cent. of the population fall into one or other of six genotypes (combinations of $\mathrm{Rh}_{1}$, $\mathrm{Rh}_{2}$ and $\mathrm{rh}$ ), whilst the other 22 are distributed among the remaining 7 per cent.

$\mathrm{Rh}^{\mathbf{1}}$ and $\mathrm{Rh}^{11}$ cells should be considered as $\mathrm{Rh}$ negative in the possible recipient of a transfusion, but as $R h$ positive in a prospective donor.

\section{The Future}

The complexities of the $\mathrm{Rh}$ factor seem to be multiplying as the research advances. Further changes and alterations will necessarily have to be made in the practical application as added research discoveries lead on to wider knowledge.

\section{Analysis of 100 Cases}

When a cross section is taken through 100 cases of the writer's series, a number of interesting and also significant facts are revealed.
Of 33 primiparous $\mathrm{Rh}$ negative mothers discovered by routine $R h$ factor investigation, two were sensitized to their husband's $R h$ positive. Antibody was demonstrated in their serums, their babies developed haemolytic disease of the new born, were transfused and survived. These two cases, therefore, appear in the number of babies transfused.

Five were married to $R h$ negative husbands and so the $\mathrm{Rh}$ factor was not involved.

Of the remaining 26,12 were married to homozygous husbands, and 14 to heterozygous husbands. Of these latter, seven achieved $\mathrm{Rh}$ negative babies.

Of 19 cases thus left over, all bore live children. Six were entirely normal, but I3, although showing no clinical signs of haemolytic disease of the new born, showed marked, proved and progressive anaemia; three at birth and the others by the fourth to eighth week. All were treated with anahaemin injections and iron by mouth, and have done well.

That such a large proportion showed progressive anaemia gives ground for conjecture, but only a further pregnancy will show whether or not it meant that these mothers had been sensitized by their first conception and whether, in their second, haemolytic disease of the new born should be anticipated.

The other 67 cases were multiparae, investigated either because of their previous history or because the new-born child showed signs of haemolytic disease of the new born. Some few were $\mathrm{Rh}$ negative mothers discovered by routine examination.

(a) 12 cases proved not to have been sensitized by previous pregnancy. In five (heterozygous husbands) the first child had been $\mathrm{Rh}$ negative. In four other cases the babies showed progressive anaemia by the fourth to eighth week.

(b) 15 cases showed hydrops foetalis, maceration, death in utero, or premature stillbirth. Antibody was demonstrated in four cases, while two cases showed anti-rh combination without demonstrable antibody.

(c) Eight cases had live-born babies which died of clinical haemolytic disease of the new born before treatment could be given. In two cases antibody was demonstrated. 
(d) Two cases with previous histories suggesting haemolytic disease of the new born and with heterozygous husbands, achieved Rh negative babies. To these must be added six cases successfully but unnecessarily transfused, because it was subsequently proved that the baby was $\mathrm{Rh}$ negative. Thus eight babies in the series fall into this group.

(e) Four cases proved impossible of successful transfusion. Three had demonstrable antibody and died. One without antibody lived. This case will be featured later.

(f) 26 cases (plus two primiparous cases with antibody) showed the babies successfully transfused.

It is of importance to study in more detail these 28 cases of successful transfusion of the babies.

Four of the cases had repeated transfusion.

Three were anticipated and one not anticipated.

All four cases showed demonstrable antibody.

Two survived (one the non-anticipated case) and two died.

Of the other 24 transfused once only, 18 were anticipated and six not so. four.

Of five that died, antibody was detected in

Of 19 that lived, antibody was proved in five cases, while in six cases transfused at birth the transfusion was afterwards proved unnecessary because the baby was Rh negative, the same genotype as the mother.

Thus I 3 successes can be claimed out of 24 , and 15 out of 28 cases.

So, of 55 cases of proved or expected haemolytic disease of the new born, 33 babies perished. Of the 22 survivors, 2 I were transfused, six unnecessarily, and in the other one transfusion was impossible, a net result of 15 successes at the utmost.

Of this series of 100 cases (33 primipara, 67 multipara), 22 cases showed antibody, incomplete antibody, or atypical antibody. Of the 22 cases, 18 babies were born alive and I3 were transfused. Seven babies survived, six died after transfusion, two died before transfusion could be managed, and in three transfusion was unsuccessfully attempted. All I I babies that died showed either proved or clinical kernicterus. The husbands' genotypes in these 22 cases are as follows :-
Homozygous $19-\mathbf{R}_{\mathbf{1}} \mathbf{R}_{\mathbf{1}}$ (10); $\mathbf{R}_{\mathbf{1}} \mathbf{R}_{\mathbf{2}}$ (8), $\mathbf{R}_{\mathbf{2}} \mathbf{R}_{\mathbf{2}}$ or $R_{2} r(I)$ ( 5 babies alive). Heterozygous $2-R_{1} r(I$ baby alive).

Anti-rh I-(baby alive).

In this series, in 27 multiparous cases with rr mothers, the babies showed clinical manifestations of haemolytic disease of the new born, but no antibody was ever demonstrable. These also must be studied in detail.

Eleven babies died prematurely of hydrops foetalis, maceration, death in utero.

The fathers proved homozygous in ten cases $\left(R_{1} R_{1}\right)$ five, $\left(R_{1} R_{2}\right)$ five and heterozygous $\left(R_{1} r\right)$ in the $I r$ th.

In six cases death of the baby anticipated treatment. The fathers' genotypes were $\left(R_{1} R_{1}\right)$ four and $\left(R_{1} R_{2}\right)$ two.

Eight cases were transfused successfully, and lived, with fathers' genotypes of $\left(R_{1} R_{1}\right)$ two, $\left(R_{1} R_{2}\right)$ four and $\left(R_{2} R_{2}\right.$ or $\left.R_{2} r\right)$ two.

One died after transfusion (father $R_{1} R_{1}$ ) and one lived after failure to transfuse. In four of the babies that died kernicterus was proved by autopsy.

In the series four Caesarean sections were performed. One was a third operation for contracted pelvis, in which the history suggested two previous foetal deaths from haemolytic disease of the new born. The child was transfused at birth, but proved $\mathrm{Rh}$ negative the same as the mother, and so transfusion was unnecessary. The other three cases were planned Caesarean sections at 38th week because of detected antibody in the mothers' serum. One baby had repeated transfusion, the other two did not survive long enough to have more than one. All three died of kernicterus.

\section{Illustrative Cases}

\section{A. Sensitized PRIMiparae}

Mrs. E.L. (Anticipated case).

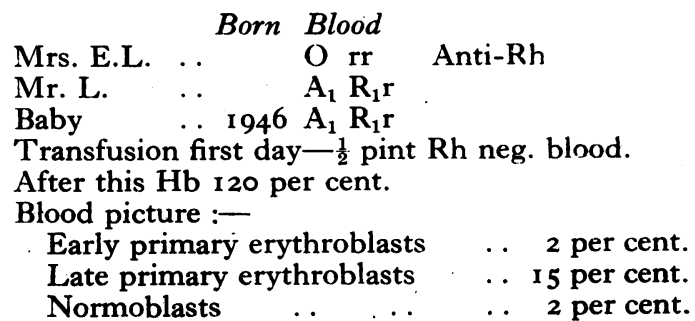


At eight weeks $\mathrm{Hb}$. 62 per cent. Gradually rose on increased doses of anahaemin and iron by mouth.

Six months Hb. 68 per cent.

This baby has not been attending for routine examination and treatment, and typifies the recurrence of anaemia that may happen about the sixth month of life.

Mrs. R.A.K. (Anticipated case).

\section{Born Blood}

Mrs. R.A.K. A rr Trace antibody.

Mr. K. , . $\quad$ B $\mathbf{R}_{1} \mathbf{R}_{2}$

Baby ' . $1946 \mathrm{~B} \cdot \mathrm{R}_{2} \mathrm{r}$

Transfusion first day $-\frac{1}{2}$ pint Rh neg. blood.

Four weeks $\mathrm{Hb} .92$ per cent.

Nine weeks $\mathrm{Hb}$. 66 per cent.

With increased doses of anahaemin and iron rose to 94 per cent. at four months.

B. Non-SENSITIZED MUltiparae

Mrs. L.A.

Mrs. L.A. . ${ }^{\text {Born }}$ B rood

Mr. A. $\quad$. $\quad$ A $\mathbf{R}_{\mathbf{1}} \mathbf{r}$

Sheila $\quad \ldots \quad$ AB rr

Baby .. 1946 O R $\mathrm{R}_{1}$ Normal, female.

- Note that first baby was $R h$ negative.

Mrs. S.B.

Born Blood

Mrs. S. B. .. O O rr

$\begin{array}{lllll}\text { Mr. B. } & \ldots & \text { B } & \mathbf{R}_{2} \mathbf{R}^{1} \\ \text { Beryl } & \ldots & \text { O } & \mathbf{R}^{1} \mathbf{r} \\ \text { Baby } & \ldots & 1946 & \text { B } & R_{2} \mathbf{r}\end{array}$

At six weeks $\mathrm{Hb}$ had fallen to 62 per cent.

With anahaemin and iron $\mathrm{Hb}$. had risen to 90 per cent. at four months.

This typifies the marked and progressive anaemia that may occur in some non-sensitized cases.

C. Cases Showing hydrops foetalis, maceration, DEATH in utero

Mrs. A.B. (Anticipated case).

\section{Born Blood}

Mrs. A.B. . . $1907 A_{1}$ rr

Mr. B. $\quad$. $1907 A_{1} R_{1} R_{2}$

I930 $\quad$ Full term. Normal delivery. Alive and well.

$1933 A_{1} R_{1} r \quad$ Full term. Normal

delivery. Alive and well.

I937 Full term. Normal delivery. Lived I 5 minutes.

$1938 \quad$ Full term. Normal delivery. Icterus neonatorum.

Died third day.
1940

I94I

1943

1944

1945

Full term. Normal delivery. Macerated.

Full term. Normal delivery. Stillbirth.

32 weeks. Normal delivery. Stillbirth.

Full term. Normal delivery. Stillbirth.

Premature stillbirth.

Mrs. C.N.T. (Anticipated case).

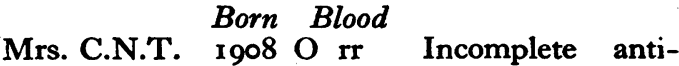
body $1: 2$.

$\begin{array}{llllll}\text { Mr. T. } & \ldots & 1897 & B & R_{1} R_{1}\end{array}$

I930 Full term. Stillborn.

$1934 \quad 3 / 12$ abortion.

- 1935 B $R_{1} \mathbf{r}$ Full term. Norma! delivery. Alive, mentally unsound.

1937 Full term. Macerated.

193936 weeks. Macerated.

$1943 \quad 36$ weeks. Macerated.

1945 Induced 36 weeks. Macerated.

Mrs. I.A.N. (Non-anticipated case).

Born Blood

Mrs. I.A.N. I909 O rr Anti-Rh (I :

I6,000)

$\begin{array}{llllll}\text { Mr. N. } & \ldots & 1908 & \mathrm{O} & \mathbf{R}_{1} \mathbf{R}_{2}\end{array}$

Jean $\quad \ldots \quad r 928$ O $\mathbf{R}_{2} \mathbf{r}$ Full term. Normal delivery. Alive and well.

Mary $\quad \ldots$ I93 $\quad 0 \quad R_{2} r \quad$ Full term. Normal delivery. Alive and well.

Violet $\quad \ldots \quad 1932 O \quad R_{1} r \quad$ Full term. Normal delivery.

1940 Full term. S.B.

1944 Full term. Normal delivery. Jaundice 3 rd day, lasted 14 days. Alive and well.

1945

S.B. Macerated. 34 weeks.

Admitted with puerperal sepsis and P.P.H. transfused with matched blood; transfusion reaction after a few ccs. Matched blood proved $\mathrm{Rh}$ positive. Packed cell transfusion of $R h$ negative blood given successfully. 
Mrs. M.L. (Non-anticipated case).

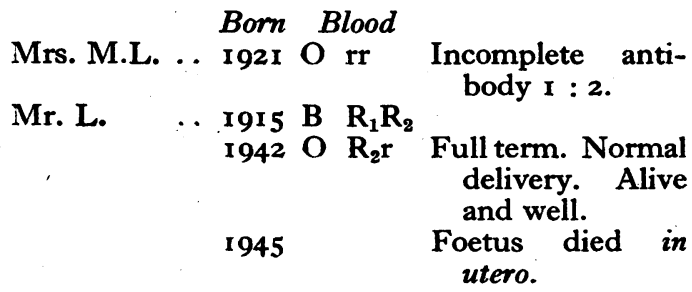

D. BABIES BORN ALIVE, BUT WHICH DIED BEFORE TRANSFUSION COULD BE AFFECTED .

Mrs. B.P. (Non-anticipated case).

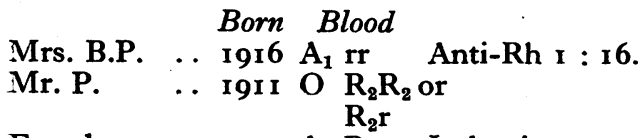

Female $\quad \ldots \quad r 939 A_{1} R_{2} r$ Induction at term for pre-eclampsia. Alive and well.

Male $\quad \ldots \quad r 944 O \quad R_{2} r \quad$ No jaundice at birth. Slight jaundice ist day. Deep jaundice and dead 3 rd

Autopsy-kernicterus. day.

Mrs. D.R. (Non anticipated case).

$$
\text { Born Blood }
$$

Mrs. D.R. . . 1923 O rr

Mr. D.R. . . 1922 O $R_{1} R_{1}$

$$
\begin{aligned}
& \text { I943 Full term. Normal } \\
& \text { delivery. Alive } \\
& \text { and well. }
\end{aligned}
$$

$1944 O R_{1}$, Full term. Normal delivery. Jaundiced at birth.

Clinical signs of kernicterus. Died and day.

Baby's serum showed traces of antibody.

Autopsy-haemolytic disease of the new born.

At no time could antibody be demonstrated in mother's blood.

E. Rh NEGATIVE MULTIPARAE MATED WITH HETEROZYGOUS HUSBANDS WITH PREVIOUS HISTORY SUGGESTING HAEMOLYTIC DISEASE OF THE NEW BORN, BUT WHO ACHIEVED AN Rh NEGATIVE CHILD.

Mrs. C.F. (Anticipated case), contracted pelvis.

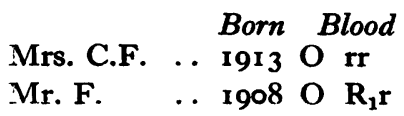

1934 Caesarean section at term. Baby' jaundiced, lived 2 days.
1936

Caesarean section at term. Baby jaundiced, lived I day.

- 1945 O rr

Caesarean section at term. Alive and well.

Transfused at birth- $-\frac{1}{2}$ pint $\mathrm{Rh}$ negative blood. An unnecessary transfusion.

Mrs. F.C. (Anticipated case).

$$
\begin{aligned}
& \text { Mrs. J.C. . Born Blood } \\
& \text { Mr. C. } \quad \ldots \quad \text { B } \mathbf{R}_{2} \mathbf{R}_{2} \text { or }
\end{aligned}
$$

1944 Normal delivery. Stillborn.

r946 O rr Alive and well.

Transfused at birth $-\frac{1}{2}$ pint $\mathrm{Rh}$ negative blood. An unnecessary transfusion.

F. Transfusion unsuccessfully attempted

Mrs. D.E. (Non-anticipated case). Born Blood

Mrs. D.E. .. A rr Demonstrable

Mr. E. $\quad$.. $\quad A \quad R_{1} R_{2}$

Jean $\quad \cdots \quad$ A $\mathbf{R}_{\mathbf{2}} \mathbf{r}$

Baby $\quad \ldots 19460 R_{2} r$ Died 40 hours. Kernicterus.

Mrs. F.D.F. (Anticipated case).

Mrs. J.D.J. Born Blood Anti-Rh I : 8

Mr. J..$\quad$ A $R_{1} r$

Rose.. .. 1943 O $R_{1} r$ Alive and well.

Richard .. r 944 A $R_{1} r$ Jaundiced at birth. Transfused. Alive and well.

1946 37-38 weeks. Jaundiced at birth. Died 2nd day.

G. REPEATED tRansfusion With UNSUCCESSFUl RESULTS

Mrs. V.S. (Anticipated case).

\section{Born Blood}

Mrs. V.S. .. I917 $A_{1}$ rr Anti-Rh I : 256.

Mr.S. .. $1916 O^{2} R_{1} R_{1}$ 1938

Full term. Normal delivery. Jaundiced, died $5^{\text {th }}$ day.

1940

Full term. Normal delivery. Jaundiced, died $5^{\text {th }}$ day.

$1942 \quad$ Full term. Normal delivery. Jaundiced, died $5^{\text {th }}$ day. 
Baby S. $\quad \ldots \quad 1943$ A $R_{1} r \quad$ Full term. Normal delivery. Jaundiced, died $4^{\text {th }}$ day.

Transfused first day-200 ccs. $\mathrm{Rh}$ negative blood, third day -200 ccs. Rh negative blood.

Autopsy-kernicterus.

Breast milk showed anti-Rh ( $1: 16)$.

Mrs. D.M.C. (Anticipated case).

Born Blood

Mrs. D.M.C. $1912 A_{1}$ rr Incomplete antibody $\mathbf{I}: \mathbf{I}$.

Mr.S.O.C. .. 1910 $O \quad R_{1} R_{1}$

J.S.C. $\quad \ldots \quad r 942 \quad A_{1} R_{1} r$ Jaundiced at birth. Transfused with father's blood daily for a week. Alive and well.

Baby C. .. $1945 \quad A_{1} R_{1} r \quad$ Planned Caesarean section. Died $4^{\text {th }}$ day.

Transfused Ist day-6o ccs. $\mathrm{Rh}$ negative blood, second day -25 ccs. Rh negative blood.

Autopsy-haemolytic anaemia.

H. Successfully transfused, But died

Mrs. H.B. (Non-anticipated case).

Born Blood

Mrs. H.B. .. I9I4 A rr Anti-Rh I : I.

Mr. B. . I I914 O $R_{1} R_{1}$

${ }_{1938} \quad$ Full term. Normal delivery.

1940 Full term. Normal Qelivery. Jaundiced 4 weeks.

I 945 A $R_{1} r$ Full term. Normal delivery. Jaundiced and day. Died 4th day.

Seen fourth day-clinical kernicterus.

Transfused with $\mathrm{Rh}$ negative blood, $\frac{1}{2}$ pint.

Mrs. M.B. (Non-anticipated case).

\section{Born Blood}

Mrs. M.B. . . I912 $A_{2}$ rr Traces Anti-Rh.

Mr. B.

$1913 A_{1} R_{1} R_{1}$

1933

1937

1939

Alive and well.

Alive and well.

Developed jaundice 3 rd day. Paralysed.

$1944 A_{1} R_{1} r$ Jaundice appeared 2 hours and deepened rapidly. Died 3rd day.

Transfused second day- $\frac{1}{2}$ pint $\mathrm{Rh}$ negative blood.

Clinical signs of kernicterus̀.
I. Transfused successfully, with babies alive AND WELL.

Mrs. R.A.R. (Non-anticipated case).

$$
\text { Born Blood }
$$

Mrs. R.A.R. I919 O rr Agglutinin present but demonstrable at room or refrigeration temperature only.

$\begin{array}{lllll}\text { Mr. R. } \quad . \quad & 1918 \text { A } & R_{1} R_{2} \\ & & 1943 & & \\ & & & \\ & & A 45 & R_{1} r\end{array}$

Alive and well.

Normal delivery. Jaundice and marked anaemia 2nd day. Blood film consistent with diagnosis of icterus gravis neonatorum.

Transfused second day with roo ccs. Rh negative blood. Still marked jaundice and anaemia.

Transfused third day with $200 \mathrm{ccs}$. Rh negative blood. Fifth day-Hb. 80 per cent. Seventh day -Hb. 65 per cent.

Transfused with 130 ccs. $\mathrm{Rh}$ negative blood seventh day. Ninth day-Hb. 85 per cent. Eleventh day-Hb. 70 per cent.

Transfused eleventh day with I00 ccs. Rh negative blood. Thirteenth day-Hb. Ioc per cent.

Anahaemin and iron dosage persisted with. At four weeks-Hb. 68 per cent.

'Transfused with $25^{\mathrm{C}} \mathrm{ccs}$. $\mathrm{Rh}$ negative blood. two days later-Hb. 85 per cent. At eight weeks -Hb. 70 per cent.

Massive doses of anahaemin and iron persisted with. Hb. percentage gradually rose.

At six months of age-Hb. 96 per cent. Blood picture entirely normal.

This baby is now a healthy and apparently normal child.

Mrs. K.F. (Non-anticipated case).

$$
\begin{aligned}
& \text { Born Blood } \\
& \text { Mrs. K.F. . . O rr } \\
& \text { Mr. F. } \quad \ldots \quad \text { O } R_{1} r \\
& 1942 O R_{1} r \quad \text { Alive and weli. } \\
& 1946 O R_{1} r
\end{aligned}
$$

Baby seen fifth day suffering from icterus gravis neonatorum.

Transfused same day-240 ccs. $\mathrm{Rh}$ negative blood. After this $\mathrm{Hb}$. 106 per cent.

Three weeks-Hb. 56 per cent. Transfusion unsuccessfully attempted.

Four weeks-Hb. 52 per cent. Small transfusion via anterior fontanelle.

Intensive anahaemin and iron persisted with.

Six months-Hb. 100 per cent. 
Mrs. E.F.G. (Anticipated case, via routine examination).

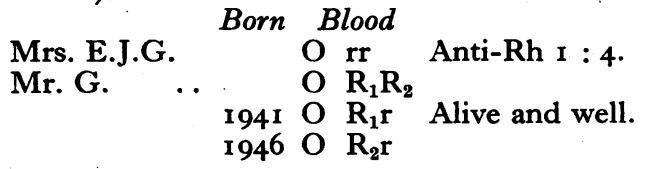

Transfused at birth-240 ccs. $\mathrm{Rh}$ negative blood. After this Hb. I54 per cent.

Four weeks, Hb. 84 per cent.-anahaemin and iron commenced.

Eight weeks, Hb. 62 per cent.-treatment intensified.

Five months, Hb. 96 per cent.

Six months, $\mathrm{Hb}$. 86 per cent.

This typifies the anaemia which may recur about the sixth month of life.

\section{J. ANTI-rh REACTION}

Mrs. C.B. (Anticipated case).

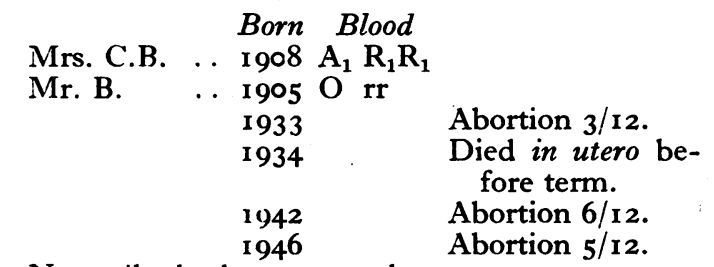

No antibody demonstrated.

Mrs. P.E. (Anticipated case).

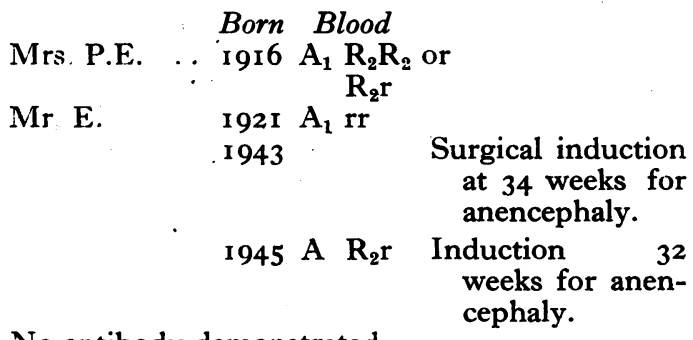

No antibody demonstrated.

Mrs. N.P. (Anticipated case). Infantile paralysis as a child.

\begin{tabular}{|c|c|c|c|}
\hline \multirow[t]{3}{*}{$\begin{array}{l}\text { Mrs. N.P. } \\
\text { Mr. P. }\end{array}$} & \multicolumn{2}{|c|}{ 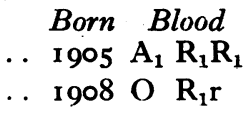 } & Anti-rh I : 8 \\
\hline & 1944 & & $\begin{array}{c}\text { S.B. } 36 \text { weeks } \\
\text { breech. }\end{array}$ \\
\hline & 1945 & $R_{1} r$ & $\begin{array}{l}\text { Extended breech, } \\
\text { induced 39th } \\
\text { week, due to } \\
\text { sharp rise in } \\
\text { titre of anti- } \\
\text { body. }\end{array}$ \\
\hline
\end{tabular}

Transfusion at birth-I40 ccs. $R_{1} R_{1}$ blood. Jaundice appeared second day, deepened rapidly. Deep jaundice fifth day, cleared at tenth. Child gaining weight, but getting transparently anaemic. Hb. I20 after transfusion. Fell rapidly despite anahaemin $\frac{1}{2}$ cc. daily plus ferri et ammon. cit. Two weeks, $\mathrm{Hb}$. 75 per cent.; Three weeks, $\mathrm{Hb}$. 62 per cent. Transfusion 270 ccs. $R_{1} R_{1}$ blood. Hb. 85 per cent. ; Five weeks, Hb. 65 per cent. Transfusion 280 ccs. $R_{1} R_{1}$ blood. $H b .82$ per cent., fell quickly to 72 per cent. but no lower, and then gradually rose (anahaemin and iron given continuously). Eight weeks, Hb. 88 per cent. Differential count normal.

Twelve weeks, Hb. 76 per cent.

Fourteen weeks, Hb. 72 per cent. Anahaemin intensified I cc. daily. Haemoglobin gradually rose, baby kept gaining weight.

Twenty-four weeks, $\mathrm{Hb} .92$ per cent. Blood picture normal.

Thirty-six weeks, normal child developing well.

Note :-This is the fourth discovered case of anti-rh antibody, and joins Levine's anti-Hr, Taylor's Stead (St), and Stanbury's Tong.

K. MOther SENSITIZED BY PREVIOUS TRANSFUSION.

Mrs. $M$.

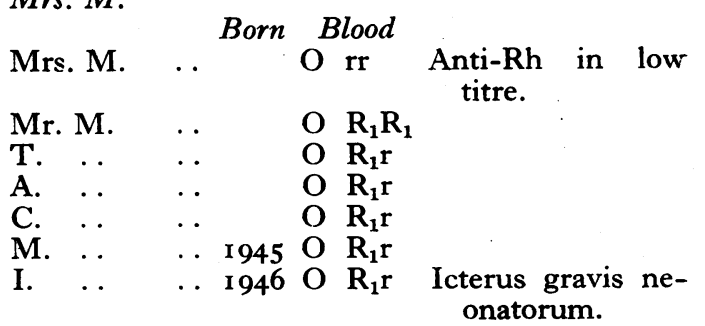

Seen fourth day. Transfused same day $-25^{\circ}$ ccs. Rh negative blood. Anahaemin and iron commenced.

Four weeks, Hb. 75 per cent. but gradually rose to 92 per cent. by four months. Mrs. M. had severe P.P.H. after fourth child and was transfused with 2 pints of type 4 blood. No reaction of any kind occurred. It is possible that this case falls into the class sensitized by transfusion. On the other hand, it may be sensitization to the husband's $R_{t}$ delayed longer than is usual.

\section{Debatable cases.}

When an $\mathrm{Rh}$ negative woman is married to a homozygous male, with genotype of different positive allelomorphs, e.g. $R_{1} R_{2}, R_{1} R^{1}$, it seems possible for her to be sensitized to one positive gene, and yet produce an unaffected child when the other gene enters into combination.

Mrs. O.A. (Anticipated case).

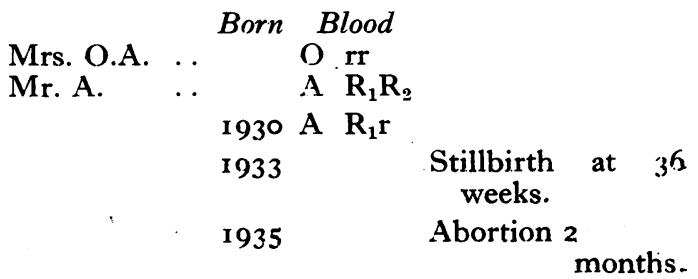




1937 Abortion 6 weeks.
1946 A $R_{2} r$.

Two attempted transfusions failed.

Eight weeks, child anaemic-Hb. 66 per cent., treated with anahaemin and iron.

Seven months - Hb. 100 per cent.

Mrs. W.L.P. (Anticipated case).

\begin{tabular}{|c|c|c|c|}
\hline \multirow[t]{3}{*}{$\begin{array}{l}\text { Mrs. W.L.P. } \\
\text { Mr. P. }\end{array}$} & Born & $\begin{array}{l}\text { Blood } \\
\quad \text { rr } \\
\mathbf{R}_{1} \mathbf{R}_{2}\end{array}$ & No antibody. \\
\hline & I 943 & & $\begin{array}{l}\text { Full term. Spina } \\
\text { bifida. }\end{array}$ \\
\hline & 1944 & . & $\begin{array}{c}\text { Premature } \\
\text { weeks. } \\
\text { hours. }\end{array}$ \\
\hline
\end{tabular}

Transfused at birth with Rh negative blood. A pint was given by error.

Fourth day, Hb. 190 per cent. Seven million R.B.C. per cub. $\mathrm{cm}$.

Eighteenth day, Hb. 125 per cent.

Three months, Hb. 93 per cent. Normal blood count.

Six months, Hb. 92 per cent. Normal blood count.

It is probable that this was also an unneceesary transfusion.

\section{Acknowledgment}

My grateful thanks for inspiration and help freely given are due to Dr. W. S. Stanbury, the previous Regional Transfusion Officer, and to his successor, Dr. R. H. Trinick.

\section{Summary and Conclusions}

(a) When a mother has been sensitized by a birth definitely affected by isoimmunization to the $\mathrm{Rh}$ factor, it will be noted that early abortion is apt to occur in subsequent pregnancies. So far, there is no proof that the $\mathrm{Rh}$ factor is a cause of abortion without previous isoimmunization having occurred. So many cases of repeated early abortion in childless women have been noted, however, where it was theoretically possible for the $R h$ factor to be involved, that there seems to be a field still open to wider research.

(b) For reasons at present unknown, haemolytic disease of the new born does not occur in all and every case where it can be anticipated, or where it is possible for it to do so. In other words, it is not known why isoimmunization occurs in some families and not in others.

(c) The sooner transfusion of the child follows its birth the better. An unnecessary transfusion, pending the determination of the baby's genotype, is worth while doing, but must not be claimed as a success.

(d) The future will bring $\mathrm{Rh}$ factor investigation in all cases of pregnancy. The factor also has an obvious medico-legal significance.

(e) Thinking people in future will have their genotypes established before marriage. Maybe the time will come in this world when as much care, thought and trouble will be taken over the breeding of the human species as is taken over the breeding of animals.

$(f)$ The problem is still in the melting pot, and the practical application of $\mathrm{Rh}$ factor will, of necessity, modify as research advances.

\section{BIBLIOGRAPHY}

BOORMAN, K. E., DODD, B. E., and MOLLISON, P. 1 . (1942), Brit. Med. F., 2, 535.

CAPPELI, D. F. (1944), Glasgow Med. J., 142, 125

GIMSON (1943), Brit. Med. Ұ., $2,293$.

JAVERT, C. T.'(1937), Amer. ̈. Obst. Gynec., 34, 1042.

LANDSTEINER, K., and WEINER, A. S. (1940), Proc. Soc.

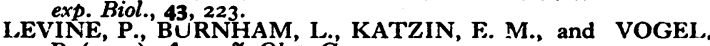
P. (1941) Amer. 7. Obst. Gynec. $42,025$.

PARSONS, HAWKSLEY, and GITTINS (1933), Arch. Nis. Childh., 8, 159.

RACE, K. R., et. alia, (1944), “ Nature” (Lond.), 153, 52

RACE, R. R.' (1944), “Nature " (Lond.), 153, 771.

RACE, R. R., and TAYLOR, G. L. (1944), Brit. Med. J., 2, 756

TAYLOR, G. L., RACE, R. R., et alia (1942), $\mathcal{F}$. Path. Bact., 54.

TAYLOR, G. I. (1944), Brit. Med. Bull., 2, 160.

WEINER, A. S. (1943), Proc. Soc. exp. Biol. Med., 54, 316.

WEINER, A. S. (1944), Proc. Soc. exp. Biol. N.Y., 56, 173 . 